УДК 556.5:549.8 (571.6)

\title{
ПИРИТ В ОСАДКАХ ОЗЕР КУРИЛЬСКИХ ОСТРОВОВ
}

\author{
П. С. Минюк \\ ФГБУН Северо-Восточный комплексный научно-исследовательский институт \\ им. Н. А. Шило ДВО РАН, г. Магадан \\ E-mail:minyuk@neisri.ru
}

\begin{abstract}
Исследованы голоценовые осадки озер Курильских островов - Пернатое (о. Парамушир), Токатан (о. Уруп), Малое и Касатка (о. Итуруп). Отложения представлены пресноводными озерными, лагунными и морскими фациями. Пирит наиболее часто встречается в отложениях лагунных и морских фаций, являясь их индикатором. Он находится в виде отдельных сфероидов и скоплений, имеющих фрамбоидальную структуру. Агрегаты пирита выполняют створки диатомей. Заполнение пиритом створок происходило постепенно.
\end{abstract}

Ключевые слова: озерный седиментогенез, пирит, голоцен, Курильские острова.

DOI: $10.34078 / 1814-0998-2021-3-44-55$

\section{ВВЕДЕНИЕ}

Пирит $\left(\mathrm{FeS}_{2}\right)$ - широко распространенный минерал в осадочных и изверженных породах. Он является индикатором аноксидных обстановок. Образование его контролируется концентрацией сульфатов, количеством и качеством органического вещества, количеством и химической активностью железосодержащих минералов, типом оксидантов (Berner, 1984; Wilkin, Arthur, 2001). В озерах он образуется в осадке на стадии диагенеза, а также встречается в водной толще выше границы осадок - вода (Wilkin, Barnes, 1997; Suits, Wilkin, 1998). Типичные реакции образования пирита, в которых задействованы сероводород, сера, водород, сульфид железа, приведены ниже (Rickard, Luther, 2007; Raven et al., 2016):

$$
\begin{gathered}
\mathrm{Fe}^{2+}+\mathrm{HS}^{-} \rightarrow \mathrm{FeS}+\mathrm{H}^{+} ; \\
\mathrm{FeS}+\mathrm{S}_{\mathrm{n}}{ }^{2-} \rightarrow \mathrm{FeS}_{2}+\mathrm{S}_{(\mathrm{n}-1)} ; \\
\mathrm{FeS}+\mathrm{H}_{2} \mathrm{~S} \rightarrow \mathrm{FeS}_{2}+\mathrm{H}_{2} ; \\
2 \mathrm{FeS}+2 \mathrm{H}^{+} \rightarrow \mathrm{FeS}_{2}+\mathrm{Fe}^{2+}+\mathrm{H}_{2} .
\end{gathered}
$$

Kроме $\mathrm{FeS}$, компонентами для образования пирита могут служить $\mathrm{FeOOH}, \mathrm{Fe}_{2} \mathrm{O}_{3}, \mathrm{Fe}(\mathrm{OH})_{3}$, фужерит, минералы железной ржавчины (Rickard, Luther, 2007). В озерных осадках пирит встречается в виде отдельных кристаллов, агрегатов, фрамбоидов, глобул (Нерадовский и др., 2008; Масленникова и др., 2012; Страховенко и др., 2015).

Фрамбоидальный пирит часто имеет биогенную природу (Southam et al., 2001; Астафьева и

(C) Минюк П. С., 2021 др., 2005), хотя он синтезирован и в лабораторных условиях химическим путем (Berner, 1969; Butler, Rickard, 2000; Ohfuji, Rickard, 2005). Рa3мер фрамбоидов часто используется как показатель физико-химических условий осадконакопления (Wilkin, Arthur, 2001).

B настоящей работе исследованы пириты озерных, морских и лагунных фаций в целях выяснения их значения для восстановления условий осадконакопления.

\section{ОБЪЕКТ ИССЛЕДОВАНИЙ}

Исследована группа прибрежно-морских озер Курильских островов: Пернатое (о. Парамушир), Малое, Касатка (о. Итуруп), Токатан (о. Уруп) (рис. 1).

Озеро Пернатое $\left(50^{\circ} 2.4^{\prime} \mathrm{N}, 155^{\circ} 23.7^{\prime} \mathrm{E}\right)$ имеет длину 1.35 км, ширину - 0.6 км, периметр - 5.6 км, площадь воды - 0.47 км², максимальную глубину -1.8 м. Осадки озера изучены геохимическим, палеомагнитным, палинологическим и диатомовым методами (Минюк и др., 2013; Anderson et al., 2015). В литологическом разрезе скв. PER3 выделены три слоя (рис. 2).

Слой 1, гл. 646-696 см. Плотный бурый торф с незначительной примесью песка содержащий пресноводные диатомеи болотных фаций Ріпnиlaria divergentissima, Eunotia exigua, E. glacialis, E. bilunaris.

Слой 2, гл. 429-646 см. В нижней части слоя (1a) (гл. 505-646 см) залегает гомогенный, массивный алеврит, в верхней части (1b) (гл. 429 505 см) - песчанистый алеврит. В слое домини- 
руют солововатоводные и морские диатомеи Melosira nummuloide, Thalassiosira kryophila, T. hyalina, T. nordenskioeldii, T. gravida, Bacterosira bathyomphala.

Слой 3, гл. 0-429 см. Бурый, песчаный алеврит с прослоями черного тонко-, среднезернистого с пресноводными диатомеями: Staurosira construens, Epithemia adnata, Cocconeis placentula var. euglypta, Staurosira construens, Staurosirella pinnata, Pseudostaurosira brevistriata, Fragilaria neoproducta. Bepxняя граница лагунных осадков на глубине 429 см отвечает максимальному подъему уровня моря в голоцене.

Озеро Малое $\left(45^{\circ} 05.2^{\prime} \mathrm{N}, 147^{\circ}\right.$ $42.0^{\prime}$ Е) имеет длину около 1600 м, ширину - 400 м, максимальные глубины - около $3 \mathrm{M}$.

В исследованном разрезе скважины выделяются три литологических слоя (см. рис. 2) (Lozhkin et al., 2017; Минюк, Борходоев, 2021).

Слой 1, гл. 1540-1085 см. Песчанистый алеврит с прослоями алевритистых песков. Отложения слоя содержат морские диатомеи, включая Paralia sulcata, Diploneis smithii, Thalassiosira nordenskioeldii, Cocconeis scutellum и др. (Lozhkin et al., 2017).

Слой 2, гл. 1085-1053 см. Слоистый алеврит. Слоистость ленточная, ясно выраженная, обусловленная гранулометрией. Отложения включают морские Paralia sulcata и солоноватоводные Melosira nummuloides, Rhoicosphenia abbreviata диатомеи, концентрация которых выше, чем в слое 1 (Lozhkin et al., 2017).

Слой 3, гл. 1053-0 см. Массивный алеврит с прослоями алевритистых песков и песчаных алевритов. Отложения сформированы в пресноводном бассейне с типичными диатомеями Cyclostephanos dubius и Staurosira construens f. venter.

Озеро Касатка имеет длину около 2400 м, ширину - 300-700 м, максимальные глубины около 5 м. В осадочном разрезе озера установлены три слоя (рис. 2).

Слой 1, гл. 892-610 см. Массивный песчаный алеврит и алевритистый песок, морские фации с диатомеями Thalassiosira trifulta, Thalassiothrix longissima, Delphineis kippae, Odontella aurita Paralia sulcata, Delphineis surirella, Thalassiosira nordenskioeldii, Thalassiosira pacifica (Lozhkin et al., 2017).

Слой 2, гл. 610-505 см. Тонкослоистый алеврит, солоноватоводные лагунные фации с диатомеями Paralia sulcata, Melosira nummuloides, Rhoicosphenia abbreviata (Lozhkin et al., 2017).

Слой 3, гл. 505-0 см. Массивный алеврит с прослоями песка, пресноводные озерные фации с диатомеями Cyclostephanos dubius, Staurosira construens f. venter, Aulacoseira granulata и др. (Lozhkin et al., 2017).

Озеро Токатан $\left(45^{\circ} 51.3^{\prime} \mathrm{N}, 149^{\circ} 47.9^{\prime}\right.$ Е) имеет длину 2.04 км, максимальную ширину - 275 м и максимальную глубину - 13 м. В разрезе дон- 


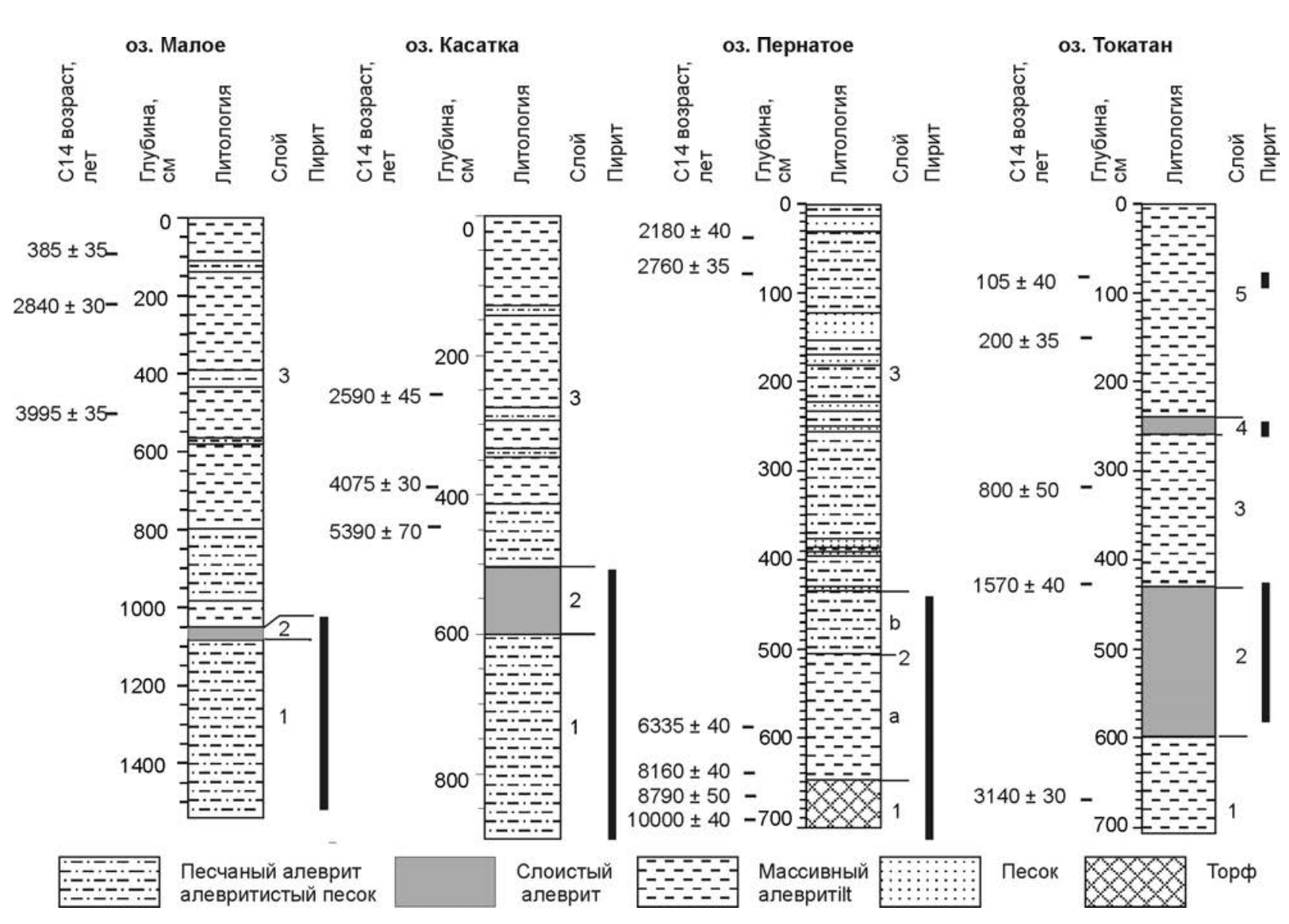

Puc. 2. Литологические колонки изученных озер Курильских островов

Fig. 2. Lythology of studied lake sediments from the Kuril Islands

ных осадков выделено 5 слоев (см. pис. 2) (Lozhkin et al., 2020).

Слои 1 (2л. 600-720 см), 3 (гл. 260-430 см) и 5 (гл. 0-240 см) представлены массивными темнокоричневыми алевритами.

Слои $2(430-600$ см) и $4(240-260$ см) сложены тонкослоистыми алевритами.

В осадках отмечены пресноводные, морские и солоноватоводные диатомеи.

\section{МЕТОДИКА ИССЛЕДОВАНИЙ}

Бурение озер проводилось модифицированным пробоотборником Ливингстона (Wright et al., 1984). Образцы из керна отобраны в пластмассовые контейнеры размерами $2 \times 2 \times 2$ см с интервалом опробования 2-2.5 см. Сульфидные минералы исследовались термомагнитными, оптическими и минералогическими методами. Термомагнитный анализ проведен на многофункциональном каппаметре MFK1-FA с термоприставкой CS-3 (AGICO). Образцы прогревались в воздушной среде. Минералогические исследования выполнены на приборе QEMSCAN (Австралия), включающем растровый микроскоп EVO50 с энергодисперсионной системой Quantax Espirit (Bruker). Слайды исследованы в проходя- щем свете на микроскопе Motic. Для приготовления слайдов использован оптический клей Norland Optical Adhesive.

\section{РЕЗУЛЬТАТЫ ИССЛЕДОВАНИЙ И ОБСУЖДЕНИЕ}

\section{Исследование сульридов в проходящем свете}

Микроскопические исследования слайдов в проходящем свете показывают, что сульфиды находятся в виде отдельных сферул и стяжений. Некоторые из них расположены в диатомеях, часто в виде цепочек, редкие имеют кубическую форму (рис. 3). Они заполняют створки диатомей различных видов. Диаметр некоторых сферул достигает 10 мкм. Сульфиды обильны в отложениях соленых и солоноватоводных фаций.

Данные показывают, что заполнение створок сульфидными сферулами происходит постепенно (рис. 4). Во многих створках встречены единичные сферулы.

В образовании пиритовых сферул выделяются три стадии. На первой стадии происходит появление зародышей пирита октаэдрических форм, во вторую стадию образуются сфероиды путем миграции элементарных частиц к месту макси- 

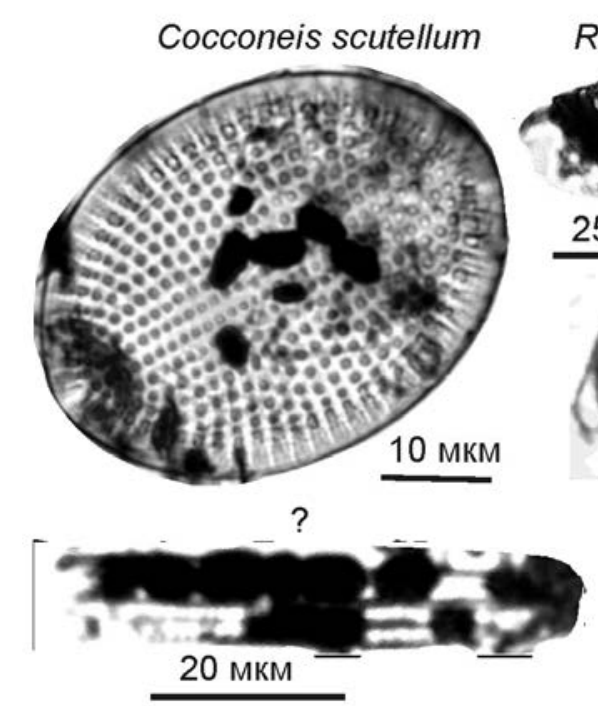

Pleurosigma/Gyrosigma?

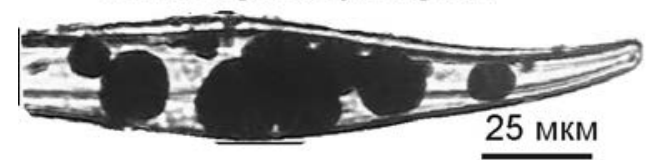

Puc. 3. Сульфиды железа в створках разных диатомей

Fig. 3. Iron sulfides in diatom valves

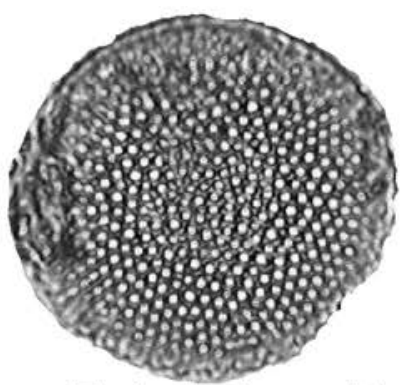

Thalassiosira gravida
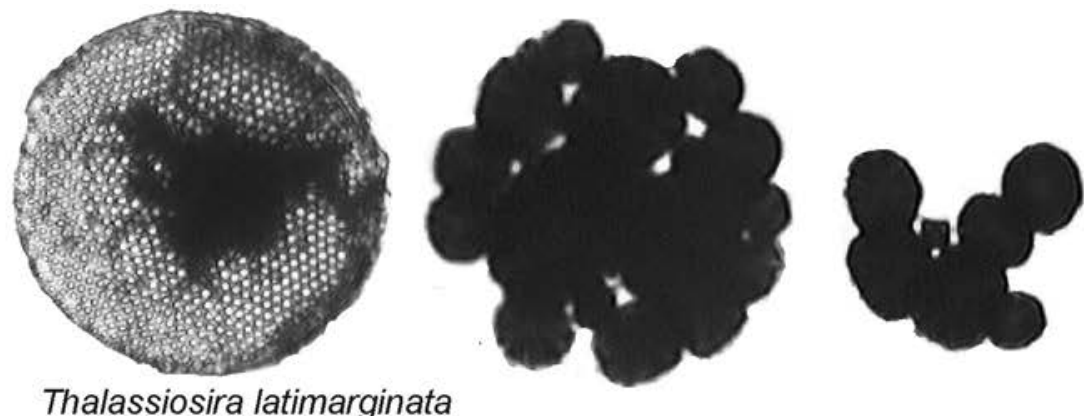

Thalassiosira latimarginata

25 мкм
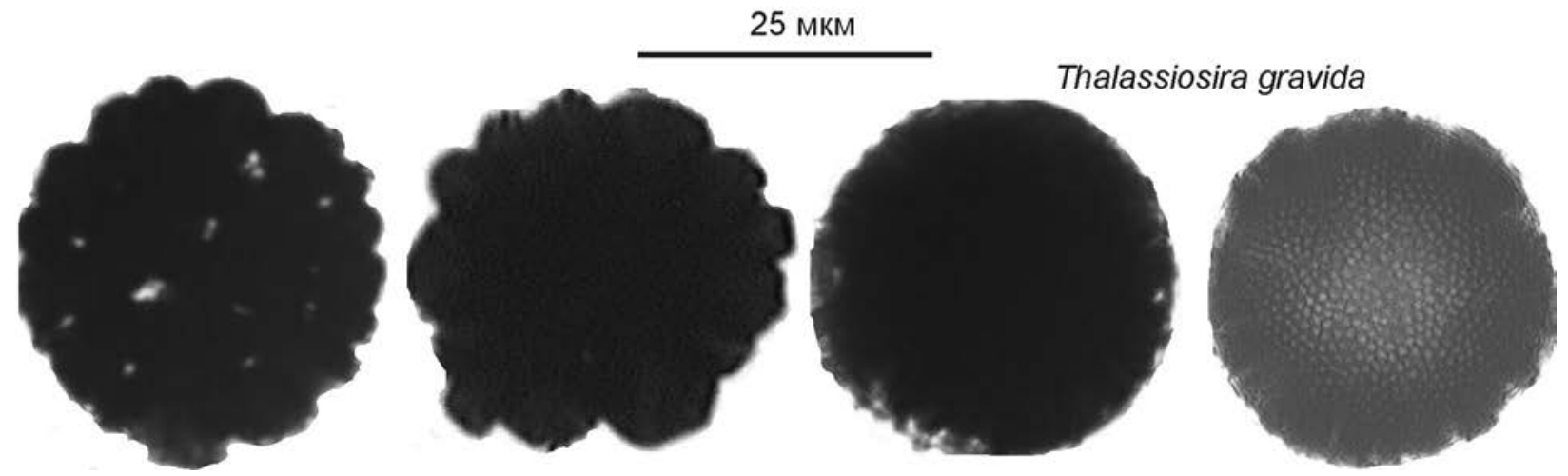

Puc. 4. Заполнение сульфидами круглых створок диатомей

Fig. 4. Sulfide filling of diatom round valves

мальной концентрации, в третью стадию сфероиды преобразуются в глобулы с уплотнением и перекристаллизацией вещества (Нерадовский и др., 2009). Наибольшее уплотнение пирита наблюдается для двух нижних створок (справа) (см. рис. 3,4$)$. 


\section{Состав и структура пирита}

Сульфидные сферулы в осадках распространены неравномерно. Часто скопления сферул приурочены к створкам диатомей. Размер сферул меньше 10 мкм. В отдельных сферулах видна фрамбоидальная структура (рис. 5,d).
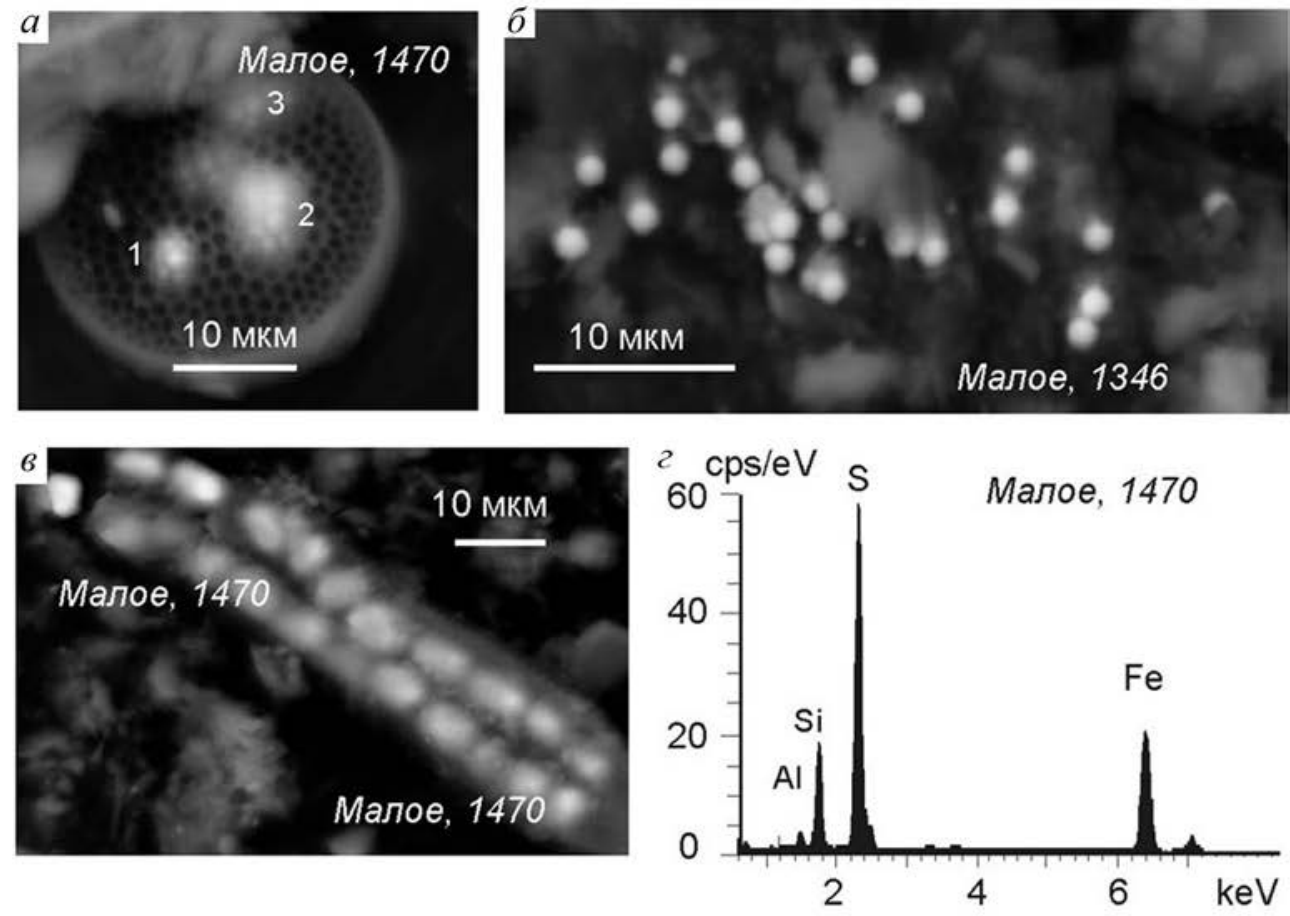

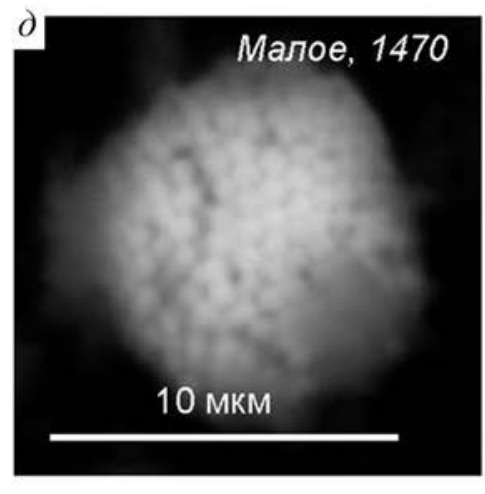

H

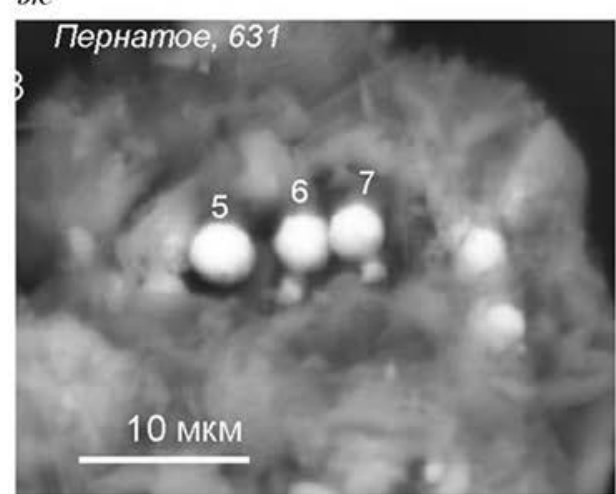

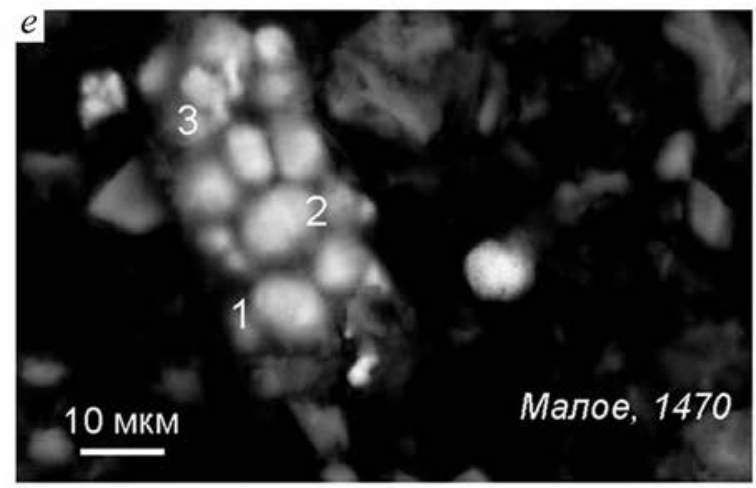

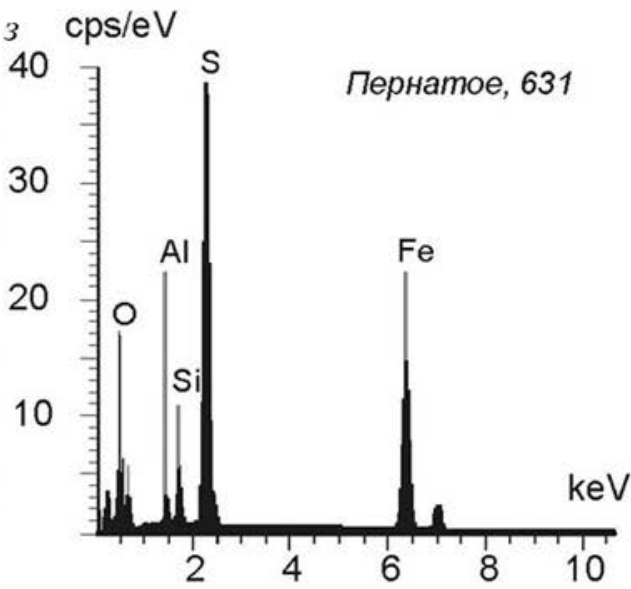

Puc. 5. Пирит в осадках озер Курильских островов: $(a-8, \partial-ж)$ - изображение в обратнорассеянных электронах; г, з - энергодисперсионные спектры

Fig. 5. Pyrite in lake sediments from the Kuril Islands: $(a-8, \partial-\varkappa))$ - back-scattered electron (BSE) image; $2, з-$ energy-dispersive spectra 
По данным энергодисперсионной рентгеновской спектроскопии сферулы состоят преимущественно из железа и серы, причем содержания серы превышают содержания железа (см. рис. $5,2,3$ ). В составах отмечается незначительная примесь алюминия, кремния, кислорода. Из-за малых размеров сферул определить точный элементный состав сферул не представляется возможным.

\section{ТЕРМОМАГНИТНЫЕ ИССЛЕДОВАНИЯ}

Пирит не стабилен к нагревам и проходит сложный путь температурных трансформаций в зависимости от среды нагрева.

В воздушной среде на разных стадиях прогрева происходит образование широкого спектра магнитных минералов: гематита, магнетита, маггемита, пирротина (Kopp, Kerr, 1958), гематита, сульфатов железа и/или пирротина (в зависимости от размера частиц) (Dunn et al., 1989a,b), гематита (Schorr, Everhart, 1969), гематита, магнетита/маггемита (Eneroth, Koch, 2003), магнетита, гематита, пирротина (Jørgensen, Moyle, 1982). Отжиг пирита в течение разного времени приводит к образованию пирротина, моносульфида железа, $\alpha-\mathrm{Fe}$, магнетита, гематита, маггемита (Prasad et al., 1985).

Исследования пирита в нагретом состоянии рентгеновским или мессбауэровским методом выявили сложный набор промежуточных минеральных фаз. В частности, мессбауэровской спектроскопией определены $\mathrm{FeSO}_{4}, \varepsilon-\mathrm{Fe}_{2} \mathrm{O}_{3}$, $\mathrm{Fe}_{2}\left(\mathrm{SO}_{4}\right)_{3}, \beta-\mathrm{Fe}_{2} \mathrm{O}_{3}, \alpha-\mathrm{Fe}_{2} \mathrm{O}_{3}$, пирротин (Ferrow, Sjoberg, 2005).

Рентгеноструктурный анализ пирита, проведенный в процессе нагрева (in situ), показал, что при нагреве в вакууме образуются гематит и магнетит (при $\mathrm{T}>400{ }^{\circ} \mathrm{C}$ ), в воздухе - гематит (при $\left.\mathrm{T}>420^{\circ} \mathrm{C}\right)$, в аргоне и азоте - пирротин (при $\mathrm{T}>$ $550{ }^{\circ} \mathrm{C}$ ), в углекислом газе - пирротин (при T > $500{ }^{\circ} \mathrm{C}$ ), магнетит (при $\mathrm{T}>600^{\circ} \mathrm{C}$ ) и гематит (при $\mathrm{T}>700{ }^{\circ} \mathrm{C}$ ) (Fegley et al., 1995; Hu et al., 2006; Bhargava et al., 2009).

При нагреве пирита наблюдается рост магнитной восприимчивости (МВ) после 420$450{ }^{\circ} \mathrm{C}$ и спад около точки Кюри магнетита, что объясняется образованием этого минерала в процессе нагрева. Кривые же остывания $\mathrm{MB}(\mathrm{T})$ характеризуются резким пирротиновым пиком при $\mathrm{T} \sim 320^{\circ} \mathrm{C}$ (например, Wang et al., 2008; Минюк и др., 2013) (рис. 6, 2).

Для выяснения температуры образования пирротина получены кривые нагрева и остывания до разных температур. Установлено, что кривые цикла прогрева до $400{ }^{\circ} \mathrm{C}$ обратимые, после $450{ }^{\circ} \mathrm{C}$ кривые остывания лежит выше нагрева - на них фиксируется образование магнети- та/маггемита. Подобные кривые получены и для 500-градусного цикла. Слабовыраженный пирротиновый пик на кривых остывания появляется лишь после $600^{\circ} \mathrm{C}$, который уже ярко выражен после цикла $700{ }^{\circ} \mathrm{C}$ (рис. 6, $a$-г).

Термомагнитные исследования осадков, включающих сульфиды, выполнены в воздушной среде. Для некоторых образцов проведены два цикла нагрева. Кривые MB(Т) характеризуются сложным строением, типичные из них показаны на рис. 6. Установлено несколько типов кривых:

1. На кривых нагрева отмечен магнетитовый рост при $\mathrm{T} \sim 420-450{ }^{\circ} \mathrm{C}$ (рис. $6, \partial, e$ ). Образованный магнетит устойчив к нагреву, о чем свидетельствует повторяемость кривых нагрева и охлаждения в интервале температур 420 $600{ }^{\circ} \mathrm{C}$. На кривых остывания заметен пирротиновый перегиб при $320{ }^{\circ} \mathrm{C}$. На кривых второго цикла пирротин не фиксируется (рис. 6, $\partial$ ). Возможно, образованный магнетит маскирует пирротиновый сигнал или же пирротин не устойчив к нагреву.

2. Для другой группы образцов рост магнитной восприимчивости наблюдается при температурах около $250-300{ }^{\circ} \mathrm{C}$ (рис. 6, ж-к). Предполагается, что этот рост обусловлен продуктами окисления пирита, предположительно лепидокрокитом $(\gamma-\mathrm{FeOOH})$, который трансформируется в маггемит-гематит (Gehring, Hofmeister, 1994; Gendler et al., 2005; Hanesch et al., 2006). Подобные кривые получены по окисленным халькопиритам (Минюк и др., 2013). Лепидокрокит, как и другие гидроксиды железа, является продуктом окисления сульфидов (Dill et al., 1997). Для этой группы образцов новообразованный моноклинный пирротин фиксируется на кривых остывания в виде роста магнитной восприимчивости при $\mathrm{T}=320^{\circ} \mathrm{C}$. Наиболее отчетливо рост отмечен на кривых первого цикла нагрева (рис. 6, ж). Для некоторых образцов он виден на кривых первого и второго циклов нагрева (рис. 6,3$)$, в единичных образцах заметен лишь на кривых второго цикла нагрева (не показаны на рисунке).

\section{Седиментационная интерпретация}

Анализ распределения сульфидов железа по осадочным колонкам исследованных озер свидетельствует о том, что эти минералы приурочены преимущественно к морским и лагунным фациям (см. рис. 2). В связи с этим пирит является индикатором палеосолености, как было отмечено ранее (Berner et al., 1979). Отметим, что сульфиды железа выявлены в осадках многих пресноводных континентальных озер Северо-Востока России - Гранд (Минюк, Борходоев, 2016; Minyuk, 


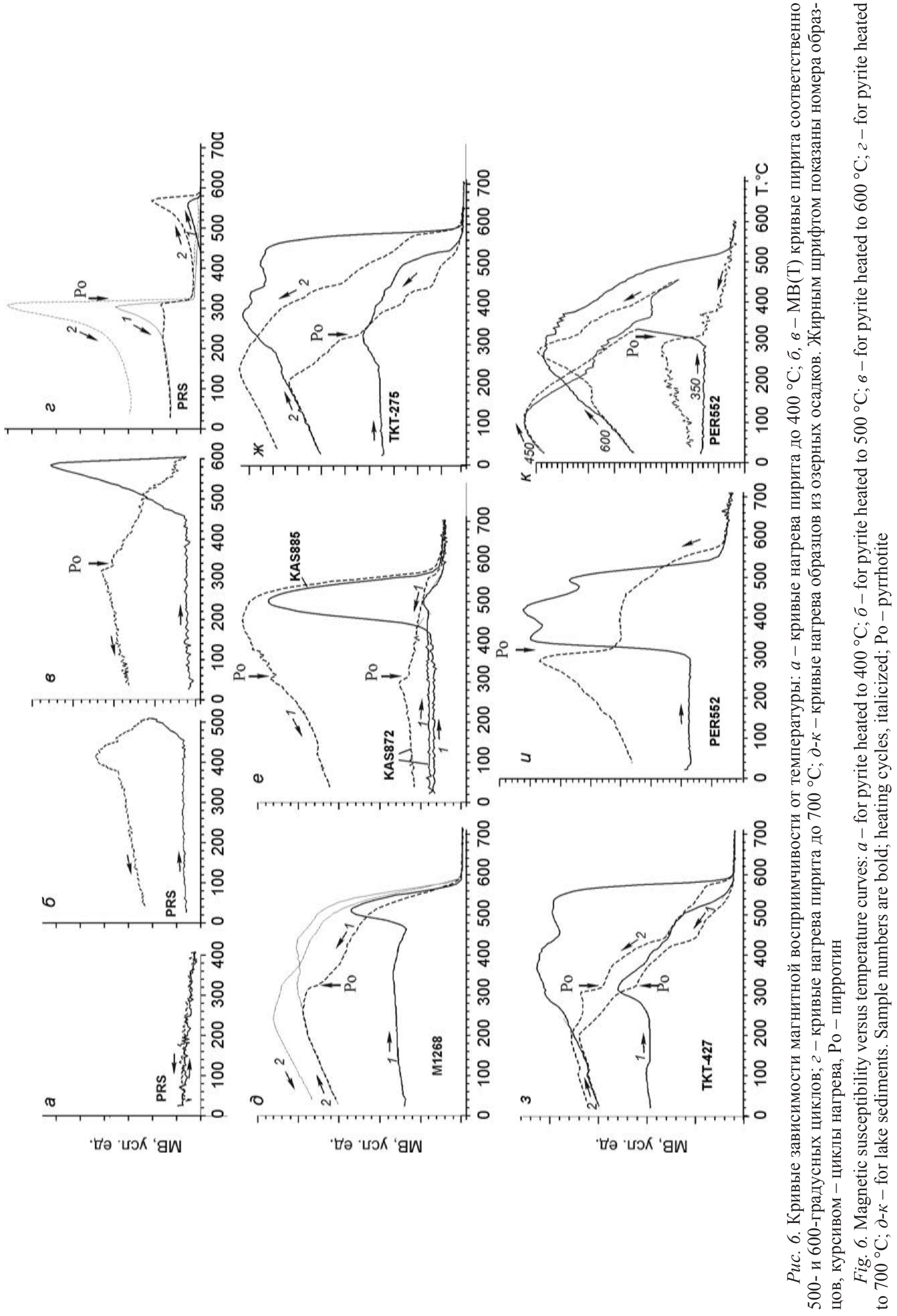


Subbotnikova, 2021), Черное, Голубое, Эльгыгытгын и др. Наличие пирита в створках диатомей предполагает, что образование пирита происходило на стадии диагенеза. Пирит является парамагнитным минералом, в связи с чем он влияет на петромагнитные свойства осадков (Минюк и др., 2013).

В осадках оз. Токатан, где чередуются диатомеи пресноводных, солоноватоводных и солоноводных диатомей, сульфиды железа встречаются по всему разрезу (см. рис. 2). Согласно термомагнитному анализу они отмечены в осадках на глубинах 85, 275, 425, 427 cм. Расположение озера вблизи береговой линии и наличие вытекающей реки из озера предполагает частое проникновение морских вод в озерный бассейн. Согласно радиоуглеродным датировкам возраст осадков ограничивается второй половиной голоцена (Lozhkin et al., 2020). В озеpax Пернатое, Малое, Касатка морские и лагунные фации занимают нижнюю часть разрезов и связаны с трансгрессиями моря (Минюк и др., 2013; Anderson et al., 2015; Lozhkin et al., 2017, 2020; Минюк, Борходоев, 2021). Экстраполированный возраст завершения морской фазы по оз. Малое составляет $6400{ }^{14} \mathrm{C}$ л. н. $(7400$ кал. лет) (Lozhkin et al., 2017), по оз. Пернатое $-6500{ }^{14} \mathrm{C}$ л. н. (Минюк и др., 2013). Этот возраст согласуется с датировками максимума морской трансгрессии на о. Кунашир - 6500$6300{ }^{14} \mathrm{C}$ л. н. ( 7400-7200 кал. лет) (Korotky et al., 2000), о. Ребун - 8000-6000 кал. лет (Schmidt et al., 2019).

\section{ЗАКЛЮЧЕНИЕ}

В осадках озер Курильских островов сульфиды железа диагностируются магнито-минералогическими и оптическими методами. Находятся сульфиды преимущественно в сфероидальных формах, фрамбоидальной морфологии, размером не более 10 мкм. Они немагнитные, по составу близкие к пириту, часто сосредоточены в створках диатомей. Заполнение сульфидами створок диатомей происходило постепенно. Наиболее часто они встречаются в морских и лагунных фациях, являясь индикатором этих отложений. Соленые и солоноватые воды, видимо, были поставщиками сульфатов, необходимых для образования пирита. Изученные пириты окислены с образованием гидроксидов железа, имеющих характерные кривые термомагнитного анализа. Просмотр слайдов в проходящем свете является наиболее быстрым методом для обнаружения сульфидных сфероидов.

Работа выполнена при финансовой поддержке РФФИ (грант 19-05-00477).

\section{ЛИТЕРАТУРА}

Астафьева М. М., Розанов А. Ю., Хувер Р. Фрамбоиды: их структура и происхождение // Палеонтологический журнал. 2005. № 5. С. 1-7.

Масленникова А. В., Блинов И. А., Удачин В. Н. Фрамбоидальный пирит в донных отложениях озер Южного Урала // Материалы IV Всероссийской молодежной научной конференции «Минералы: строение, свойства, методы исследования», 15-18 октября 2012 г. Екатеринбург : Институт геологии и геохимии им. академика А. Н. Заварицкого, 2012. № 4. С. 188-190.

Минюк П. С., Борходоев В. Я. Геохимия осадков озера Гранд, Северо-Восток России // Геохимия. 2016. № 9. C. 841-851. DOI: 10.7868/S0016752516070074

Минюк П. С., Борходоев В. Я. Реакция геохимических характеристик на изменения природной среды голоцена по данным донных отложений озера Малое, остров Итуруп // Геохимия. 2021. Т. 66 (4). С. 1-14. DOI: $10.31857 / \mathrm{S} 0016752521040051$

Минюк П. С., Субботникова Т. В., Андерсон П. М., Ложкин $A$. В. Петромагнитные свойства осадков озера Пернатое (остров Парамушир, Курильская гряда) как показатели изменений условий осадконакопления // Физика Земли. 2013. Т. 1. С. 1-10. DOI: 10.7868/ S0002333713010092

Минюк П. С., Тюкова Е. Э., Субботникова Т. В., Казанский А. Ю., Федотов А. П. Термокаппаметрия природных сульфидов железа Северо-Востока России // Геология и геофизика. 2013. Т. 54 (4). С. 601614.

Нерадовский Ю. Н., Даувальтер В. А., Савченко E. Э. Фрамбоидальный пирит в донных осадках о3. Имандра (Кольский полуостров) // Проблемы рудогенеза докембрийских щитов : Труды Всерос. науч. конф., посвящ. 90-летнему юбилею чл.-корр. РАН Г. И. Горбунова. Апатиты : КНЦ РАН, 2008. C. 56-59.

Нерадовский Ю. Н., Даувальтер В. А., Савченко $E$. Э. Генезис фрамбоидального пирита в современных осадках озер (Кольский полуостров) // Записки Российского минералогического общества. 2009. № 6. C. 50-56.

Страховенко В. Д., Солотчина Э. П., Восель Ю. С., Солотчин П. А. Геохимические факторы аутигенного минералообразования в донных отложениях озер Тажеранской системы (Прибайкалье) // Геология и геофизика. 2015. Т. 56, № 10. С. 1825-1841. DOI: 10.15372/ GiG20151006

Anderson P., Minyuk P., Lozhkin A., Cherepanova M., Borkhodoev V., Finney B. A multiproxy record of Holocene environmental changes from the northern Kuril Islands (Russian Far East) // Journal of Paleolimnology. 2015. Vol. 54. P. 379-393. DOI: 10.1007/s10933-0159858-y

Berner R. A. The synthesis of framboidal pyrite // Economic Geology. 1969. Vol. 64. P. 383-384. Doi: https:// doi.org/10.2113/gsecongeo.64.4.383

Berner R. A. Sedimentary pyrite formation: An update // Geochimica et Cosmochimica Acta. 1984. Vol. 48. P. 605-615. doi.org/10.1016/0016-7037(84) 90089-9 
Berner R. A., Baldwin T., Holdren G. R. Authigenic iron sulfides as paleosalinity indicators // Journal of Sedimentary Petrology. 1979. Vol. 49. P. 1345-1350.

Bhargava S. K., Garg A., Subasinghe N. D. In situ high-temperature phase transformation studies on pyrite // Fuel. 2009. Vol. 88. P. 988-993. DOI:10.1016/j. fuel.2008.12.005

Butler I. B., Rickard D. Framboidal pyrite formation via the oxidation of iron (II) monosulfide by hydrogen sulfide // Geochimica et Cosmochimica Acta. 2000. Vol. 64. P. 2665-2672. DOI.org/10.1016/S0016-7037(00)00387-2

Dill H. G., Eberhard E., Hartmann B. Use of variations in unit cell length, reflectance and hardness for determining the origin of Fe disulphides in sedimentary rocks // Sedimentary Geology. 1997. Vol. 107. P. 281301. doi.org/10.1016/S0037-0738(96)00031-0

Dunn J. G., De G. C., O'Connor B. H. The effect of experimental variables on the mechanism of the oxidation of pyrite : part 1. Oxidation of particles less than $45 \mu \mathrm{m}$ in size // Thermochimica Acta. 1989a. Vol. 145. P. 115-130. DOI.org/10.1016/0040-6031(89)85131-7

Dunn J. G., De G. C., O'Connor B. H. The effect of experimental variables on the mechanism of the oxidation of pyrite : part 2. Oxidation of particles of size 90$125 \mu \mathrm{m} / /$ Thermochimica Acta. 1989b. Vol. 155. P. 135149. DOI.org/10.1016/0040-6031(89)87142-4

Eneroth E., Koch C. B. Crystallite size of haematite from thermal oxidation of pyrite and marcasite - effects of grain size and iron disulphide polymorph // Minerals Engineering. 2003. Vol. 16. P. 1257-1267. doi:10.1016/j. mineng.2003.07.004

Fegley Jr. B., Lodders K., Treiman A. H., Klingelhofer $G$. The rate of pyrite decomposition on the surface of Venus // Icarus. 1995. Vol. 115. P. 159-180. DOI. org/10.1006/icar.1995.1086

Ferrow E. A., Sjoberg B. A. Oxidation of pyrite grains: A Mossbauer Spectroscopy and Mineral Magnetism Study // Hyperfine Interactions. 2005. Vol. 163. P. 95-108. DOI: 10.1007/s10751-005-9199-8

Gehring A. U., Hofmeister A. M. The transformation of lepidocrocite during heating: a magnetic and spectroscopic study // Clays and Clay Minerals. 1994. Vol. 42. P. 409-415. DOI.org/10.1346/CCMN.1994.0420405

Gendler T. S., Shcherbakov V. P., Dekkers M. J., Gapeev A. K., Gribov S. K., McClelland E. The lepidocrocite-maghemite-haematite reaction chain: I. Acquisition of chemical remanent magnetization by maghemite, its magnetic properties and thermal stability // Geophysical Journal International. 2005. Vol. 160. P. 815-832. DOI:10.1111/j.1365-246X.2005.02550.x

Hanesch M., Stanjek H., Petersen N. Thermomagnetic measurements of soil iron minerals: the role of organic carbon // Geophysical Journal International. 2006. Vol. 165. P. 53-61. DOI: 10.1111/j.1365-246X.2006. 02933.x

Hu G., Dam-Johansen K., Wedel S., Hansen J. P. Decomposition and oxidation of pyrite // Progress in Energy and Combustion Science. 2006. Vol. 32. P. 295-314. doi:10.1016/j.pecs.2005.11.004
Jørgensen F. R. A., Moyle F. J. Phases formed during the thermal analysis of pyrite in air // Journal of Thermal Analysis. 1982. Vol. 25. P. 473-485. DOI.org/10.1007/ BF01912973

Kopp O. C., Kerr P. F. Differential thermal analysis of pyrite and marcasite // The American Mineralogist. 1958. Vol. 43. P. 1079-1097.

Korotky A. M., Razjigaeva N. G., Grebennikova T. A., Ganzey L. A., Bazarova V. B., Sulerzhitsky L. D., Lutaenko $K$. A. Middle- and late-Holocene environments and vegetation history of Kunashir Island, Kurile Islands, northwestern Pacific // Holocene. 2000. Vol. 10. P. 311-331. DOI:10.1191/095968300667552216

Lozhkin A., Cherepanova M., Anderson P., Minyuk P., Finney B., Pakhomov A., Brown T., Korzun J., Tsigankova $V$. Late Holocene history of Tokatan Lake (Kuril Archipelago, Russian Far East): The use of lacustrine records for paleoclimatic reconstructions from geologically dynamic settings // Quaternary Inter-national. 2020. Vol. 553. P. 104-117. DOI.org/10.1016/j. quaint.2020.05.023

Lozhkin A., Minyuk P., Cherepanova M., Anderson P., Finney B. Holocene environments of central Iturup Island, southern Kuril Archipelago, Russian Far East // Quaternary Research. 2017. Vol. 88 (1). P. 23-38. doi:10.1017/ qua.2017.21

Minyuk P. S., Subbotnikova T. V. Rock magnetic properties of Grand Lake sediments as evidence of environmental changes during the last 60000 years in North-East Russia // Boreas. 2021. https://doi.org/10.1111/bor.12546

Ohfuji T. H., Rickard D. Experimental syntheses of framboids - a review // Earth-Science Reviews. 2005. Vol. 71. P. 147-170. doi:10.1016/j.earscirev.2005. 02. 001

Prasad A., Singru R. M., Biswas A. K. Study of the roasting of pyrite minerals by Mossbauer spectroscopy // Physica Status Solidi A. 1985. Vol. 87. P. 267-271.

Raven M. R., Sessions A. L., Fischer W. W., Adkins $J$. F. Sedimentary pyrite d34S differs from porewater sulfide in Santa Barbara Basin: Proposed role of organic sulfur // Geochimica et Cosmochimica Acta. 2016. Vol. 186. P. 120-134. dx.doi.org/10.1016/j. gca.2016.04.037

Rickard D., Luther III G. W. Chemistry of iron sulfides // Chemical Reviews. 2007. Vol. 107. P. 514-562. doi: 10.1021/cr0503658

Schmidt M., Leipe C., Becker F., Goslar T., Hoelzmann P., Mingram J., Muller S., Tjallingii R., Wagner M., Tarasov P.E. A multi-proxy palaeolimnological record of the last 16.600 years from coastal Lake Kushu in northern Japan // Palaeogeography, Palaeoclimatology, Palaeoecology. 2019. Vol. 514. P. 613-626. DOI:10.1016/j. palaeo.2018.11.010

Schorr J. R., Everhart J. O. Thermal behavior of pyrite and its relation to carbon and sulfur oxidation in clays // Journal of the American Ceramic Society. 1969. Vol. 52 (7). P. 351-354. DOI:10.1111/j.1151-2916.1969. tb11953.x

Southam G., Donald R., Röstad A., Brock C. Pyrite discs in coal: Evidence for fossilized bacterial colo- 
nies // Geology. 2001. Vol. 29. P. 47-50. DOI: 10.1130/ 0091-7613(2001)029<0047:PDICEF>2.0.CO;2

Suits N. S., Wilkin R. T. Pyrite formation in the water column and sediments of meromictic lake // Geology. 1998. Vol. 26. P. 1099-1102. doi: 10.1130/0091-7613(1998)026<1099:PFITWC > 2.3.CO;2

Wang L., Pan Y., Li J., Qin H. Magnetic properties related to thermal treatment of pyrite // Science in China. Series D: Earth Sciences. 2008. Vol. 5 (8). P. 1144-1153. DOI: $10.1007 / \mathrm{s} 11430-008-0083-7$

Wilkin R. T., Arthur M. A. Variations in pyrite texture, sulfur isotope composition, and iron systematics in the Black Sea:evidence for late Pleistocene to Holocene excursions of the $\mathrm{O}_{2}-\mathrm{H}^{2} \mathrm{~S}$ redox transition // Geochimi- ca et Cosmochimica Acta. 2001. Vol. 65. P. 1399-1416. DOI:10.1016/S0016-7037(01)00552-X

Wilkin R. T., Barnes H. L. Pyrite formation in an anoxic estuarine basin // American Journal of Science. 1997. Vol. 297. P. 620-650. /doi.org/10.2475/ ajs.297.6.620

Wilkin R. T., Barnes H. L., Brantley S. L. The size distribution of framboidal pyrite in modern sediments: An indicator of redox conditions // Geochimica et Cosmochimica Acta. 1996. Vol. 60. P. 3897-3912. DOI:10.1016/00167037(96)00209-8

Wright H. E. Jr., Mann D. H., Glaser P. H. Piston corers for peat and lake sediments // Ecology. 1984. Vol. 65. P. 657-659. DOI.org/10.2307/1941430

Поступила в редакичию 09.08.2021 2.

\title{
PYRITE FROM THE KURIL ISLANDS LAKE SEDIMENTS
}

\begin{abstract}
P. S. Minyuk
North-East Interdisciplinary Scientific Research Institute n. a. N. A. Shilo, FEB RAS, Magadan

Holocene sediments of the Kuril Archipelago lakes (Pernatoye, Paramushir Island; Tokatan, Urup Island; Maloye and Kasatka, Iturup Island) were studied. The sediments consist of freshwater lake, lagoon, and marine facies. Pyrite is most often found in sediments of lagoon and marine facies, being their indicator. It is found as separate spheroids and clusters of framboidal structure. Pyrite aggregates fill up diatom valves. Valves were filled with pyrite gradually.
\end{abstract}

Keywords: lake sedimentation, pyrite, Holocene, Kuril Islands.

\section{REFERENCES}

Anderson, P., Minyuk, P., Lozhkin, A., Cherepanova, M., Borkhodoev, V., Finney, B., 2015. A Multiproxy Record of Holocene Environmental Changes from the Northern Kuril Islands (Russian Far East), Journal of Paleolimnology. 54, 379-393.

Astafieva, M. M., Rozanov, A. Yu., Hoover, R., 2005. Framboids: Their Structure and Origin, Paleontological Journal. 39 (5), 457-464 [In Russian].

Berner, R. A., 1969. The Synthesis of Framboidal Pyrite, Economic Geology. 64, 383-384.

Berner, R. A., 1984. Sedimentary Pyrite Formation: An Update, Geochimica et Cosmochimica Acta. 48, 605615.

Berner, R. A., Baldwin, T., Holdren, G. R., 1979. Authigenic Iron Sulfides as Paleosalinity Indicators, Journal of Sedimentary Petrology. 49, 1345-1350.

Bhargava, S. K., Garg, A., Subasinghe, N. D., 2009. In Situ High-Temperature Phase Transformation Studies on Pyrite, Fuel. 88, 988-993.

Butler, I. B., Rickard, D., 2000. Framboidal Pyrite Formation via the Oxidation of Iron (II) Monosulfide by Hy- drogen Sulfide, Geochimica et Cosmochimica Acta. 64, 2665-2672.

Dill, H. G., Eberhard, E., Hartmann, B., 1997. Use of Variations in Unit Cell Length, Reflectance and Hardness for Determining the Origin of Fe Disulphides in Sedimentary Rocks, Sedimentary Geology. 107, 281-301.

Dunn, J. G., De, G. C., O'Connor, B. H., 1989. The Effect of Experimental Variables on the Mechanism of the Oxidation of Pyrite: Part 2. Oxidation of Particles of Size 90-125 $\mu \mathrm{m}$, Thermochimica Acta. 155, 135-149.

Dunn, J. G., De, G. C., O'Connor, B. H., 1989. The Effect of Experimental Variables on the Mechanism of the Oxidation of Pyrite: Part 1. Oxidation of Particles Less than $45 \mu \mathrm{m}$ in Size, Thermochimica Acta. 145, 115-130.

Eneroth, E., Koch, C. B., 2003. Crystallite Size of Haematite from Thermal Oxidation of Pyrite and Marcasite - Effects of Grain Size and Iron Disulphide Polymorph, Minerals Engineering. 16, 1257-1267.

Fegley, Jr. B., Lodders, K., Treiman, A. H., Klingelhofer, G., 1995. The Rate of Pyrite Decomposition on the Surface of Venus, ICARUS. 115, 159-180. 
Ferrow, E. A., Sjoberg, B. A., 2005. Oxidation of Pyrite Grains: A Mossbauer Spectroscopy and Mineral Magnetism Study, Hyperfine Interactions. 163, 95-108.

Gehring, A. U., Hofmeister, A. M., 1994. The Transformation of Lepidocrocite during Heating: a Magnetic and Spectroscopic Study, Clays and Clay Minerals. 42, 409-415.

Gendler, T. S., Shcherbakov, V. P., Dekkers, M. J., Gapeev, A. K., Gribov, S. K., McClelland, E., 2005. The Lepidocrocite-Maghemite-Haematite Reaction Chain: I. Acquisition of Chemical Remanent Magnetization by Maghemite, Its Magnetic Properties and Thermal Stability, Geophysical Journal International. 160, 815832.

Hanesch, M., Stanjek, H., Petersen, N., 2006. Thermomagnetic Measurements of Soil Iron Minerals: the Role of Organic Carbon, Geophysical Journal International. 65, 53-61.

Hu, G., Dam-Johansen, K., Wedel, S., Hansen, J. P., 2006. Decomposition and Oxidation of Pyrite, Progress in Energy and Combustion Science. 32, 295-314.

Jørgensen, F. R. A, Moyle, F. J., 1982. Phases Formed during the Thermal Analysis of Pyrite in Air, Journal of Thermal Analysis. 25, 473-485.

Kopp, O. C., Kerr, P. F., 1958. Differential Thermal Analysis of Pyrite and Marcasite, The American Mineralogist. 43, 1079-1097.

Korotky, A. M., Razjigaeva, N. G., Grebennikova, T. A., Ganzey, L. A., Bazarova, V. B., Sulerzhitsky, L. D., Lutaenko, K. A., 2000. Middle- and Late-Holocene Environments and Vegetation History of Kunashir Island, Kurile Islands, Northwestern Pacific, Holocene. 10, 311-331. DOI:10.1191/095968300667552216.

Lozhkin, A., Cherepanova, M., Anderson, P., Minyuk, P., Finney, B., Pakhomov, A., Brown, T., Korzun, J., Tsigankova, V., 2020. Late Holocene History of Tokatan Lake (Kuril Archipelago, Russian Far East): The Use of Lacustrine Records for Paleoclimatic Reconstructions from Geologically Dynamic Settings, Quaternary International. 553, 104-117.

Lozhkin, A., Minyuk, P., Cherepanova, M., Anderson, P., Finney, B., 2017. Holocene Environments of Central Iturup Island, Southern Kuril Archipelago, Russian Far East, Quaternary Research. 88 (1), 23-38.

Maslennikova, A. V., Blinov, I. A., Udachin, V. N., 2012. Framboidal Pyrite in Bottom Sediments of Lakes of the Southern Urals, Minerals: Structure, Properties, Research Methods, Materials of the IV All-Russian. Youth. Scientific Conference, October 15-18, 2012. RAS, UrO, Institute of Geology and Geochemistry. akad. A. N. Zavaritsky. Yekaterinburg, 4, 188-190 [In Russian].

Minyuk, P. S., Borkhodoev, V. Ya., 2016. Geochemistry of Sediments from Lake Grand, Northeast Russia, Geochemistry International. 54 (9), 807-816 [In Russian].

Minyuk, P. S., Borkhodoev, V. Ya., 2021. Response of Geochemical Characteristics on the Environmental Changes in the Holocene: Data on Bottom Sediments of Lake Maloe, Iturup Island, Geochemistry International. 59 (4), 422-434.
Minyuk, P. S., Subbotnikova, T. V., 2021. Rock Magnetic Properties of Grand Lake Sediments as Evidence of Environmental Changes during the Last 60000 Years in North-East Russia, Boreas. https://doi.org/10.1111/ bor. 12546

Minyuk, P. S., Subbotnikova, T. V., Anderson, P. M., Lozhkin, A. V., 2013. Rock Magnetic Properties of the Lake Pernatoe Sediments (Paramushir Island) as an Indicator of the Changes in Sedimentation Conditions, Izvestiya, Physics of the Solid Earth. 49 (1), 120-129 [In Russian].

Minyuk, P. S., Tyukova, E. E., Subbotnikova, T. V., Kazansky, A. Yu., Fedotov, A. P., 2013. Thermal Magnetic Susceptibility Data on Natural Iron Sulfides of Northeastern Russia, Russian Geology and Geophysics. 3, 54, 464 474 [In Russian].

Neradovsky, Yu. N., Dauvalter, V. A., Savchenko, E. E., 2008. Framboidal Pyrite in the Bottom Sediments of Lake Imandra (Kola Peninsula), Problems of Ore Genesis of Precambrian Shields, Proceedings of the All-Russia Scientific Conference Dedicated to the $90^{\text {th }}$ Anniversary of Corresponding Member of the Russian Academy of Sciences G. I. Gorbunov. Apatity, KSC RAS. 56-59 [In Russian].

Neradovsky, Yu. N., Dauvalter, V.A., Savchenko, E. E., 2009. Genesis of Framboidal Pyrite in the Contemporary Lake Deposits (Kola Peninsula), Zapiski RMO. 6, 50-56 [In Russian].

OhfujiT, H., Rickard, D., 2005. Experimental Syntheses of Framboids - a Review, Earth-Science Reviews. 71, 147-170.

Prasad, A., Singru, R. M., Biswas, A. K., 1985. Study of the Roasting of Pyrite Minerals by Mossbauer Spectroscopy, Physica Status Solidi A. 87, 267-271.

Raven, M. R., Sessions, A. L., Fischer, W. W., Adkins, $J$. F., 2016. Sedimentary Pyrite $\mathrm{d}^{34} \mathrm{~S}$ Differs from Porewater Sulfide in Santa Barbara Basin: Proposed Role of Organic Sulfur, Geochimica et Cosmochimica Acta. 186, 120-134.

Rickard, D., Luther, III G. W., 2007. Chemistry of Iron Sulfides, Chemical Reviews. 107, 514-562.

Schmidt, M., Leipe, C., Becker, F., Goslar, T., Hoelzmann, P., Mingram, J., Muller, S., Tjallingii, R., Wagner, M., Tarasov, P. E., 2019. A Multi-Proxy Palaeolimnological Record of the Last 16.600 Years from Coastal Lake Kushu in Northern Japan, Palaeogeography, Palaeoclimatology, Palaeoecology. 514, 613-626. DOI:10.1016/j. palaeo.2018.11.010

Schorr, J. R., Everhart, J. O., 1969. Thermal Behavior of Pyrite and Its Relation to Carbon and Sulfur Oxidation in Clays, Journal of the American Ceramic Society. 52 (7), 351-354.

Southam, G., Donald, R., Röstad, A., Brock, C., 2001. Pyrite Discs in Coal: Evidence for Fossilized Bacterial Colonies, Geology. 29, 47-50.

Strakhovenko, V. D., Solotchina, E. P., Vosel, Y. S., Solotchin, P. A., 2015. Geochemical Factors for Authigenic Mineral Formation in the Bottom Sediments of the Tazheran Lakes ( Pribaikalye), Russian Geology and Geophysics. 56 (10), 1437-1450 [In Russian]. 
Suits, N. S., Wilkin, R. T., 1998. Pyrite Formation in the Water Column and Sediments of Meromictic Lake, Geology. 26, 1099-1102.

Wang, L., Pan, Y., Li, J., Qin, H., 2008. Magnetic Properties Related to Thermal Treatment of Pyrite, Science in China. Series D: Earth Sciences. 5 (8), 1144-1153.

Wilkin, R. T., Arthur, M. A., 2001. Variations in Pyrite Texture, Sulfur Isotope Composition, and Iron Systematics in the Black Sea: Evidence for Late Pleistocene to Holocene Excursions of the $\mathrm{O}_{2}-\mathrm{H}^{2} \mathrm{~S}$ Redox Transition, Geochimica et Cosmochimica Acta. 65, 1399-1416.
Wilkin, R. T., Barnes, H. L., 1997. Pyrite Formation in an Anoxic Estuarine Basin, American Journal of Science. 297, 620-650.

Wilkin, R. T., Barnes, H. L., Brantley, S. L., 1996. The Size Distribution of Framboidal Pyrite in Modern Sediments: An Indicator of Redox Conditions, Geochimica et Cosmochimica Acta. 60, 3897-3912.

Wright, H. E. Jr., Mann, D. H., Glaser, P. H., 1984. Piston Corers for Peat and Lake Sediments, Ecology. 65, 657-659. 